\title{
The Monitoring System Design of the Traction Transformer Power Loss
}

\author{
H.G. Lai, \\ School of Mechanical Eng ineering Ning xia University \\ Ning xia, Yinchuan, China
}

\begin{abstract}
The train mixed operation on the electrified railway road network of general speed, resulting in frequent action of overload protection of substation traction transformer. This paper designed the engineering framework under the traction transformer power loss of economic operation, by means of the configuration software rich characteristics. The object oriented framework is constructed. The target of real-time / historical data and curve graphics interface is realized by the definition of data objects. The traction transformer monitoring system for high performance, high reliability and highly specialized is designed configuration. Simulation results show that the visualization of data and processes to meet the needs assessment traction transformer economic operation state, especially the digital traction transformer protection monitoring reconstruction.
\end{abstract}

Keywords-traction transformer; economic operation; power loss, monitoring; configuration

\section{INTRODUCTION}

Along with the interconnection of Chinese region economy, high-speed rail network also built more and more in Chinese area, but has not formed a national network scale. On parts of Chinese western and middle and eastern, China Railway High-Speed (CRH) train and electric multiple unit (EMU) train running on general speed railway network, the traction power supply ability for general speed electrified railway is a very big test. Domestic and foreign relevant research specialists have been continuously published relative research findings on recent years [1 8]. Consensus is: $\mathrm{CRH}$, EMU and heavy haul train through train to make the design ability of traction load of general speed railway network rapid saturation or short term exceeded the long term design goals. The electrified railway traction power supply uninterrupted power supply ability and the power supply quality is deteriorated, which interferes with the traction power supply network normal operation order, while increasing the capacity overhead of the local power supply system. The literature [1-3] is more concerned with how does not change in the basis capacity of traction transformer; reas onably determine the ratio of traction transformer overload, adjustment protection setting, improvement of train tracking interval. The literature [4-7]pput forward that overload and life losses of traction transformer were related [4], needed to improve the traction transformer capacity[5], the equipment state monitoring network or system health monitoring and evaluation needs to include the traction transformer monitor [6 7]. But for the traction transformer and traction load saving power mechanism and monitoring control analys is is negative.

\author{
X.J. Zhu \\ School of Mechanical Eng ineering Ning xia University \\ Ning xia, Yinchuan, China
}

The literature [8] presented in transformer state assessment, in addition to static numerical state (experimental data, operation information, historical data, family defect), parts state parameters vary trend is also important factors to affect the evaluation result. The online detection and state assessment of transformer combined will help to improve the timeliness and the accuracy of the transformer state assessment. The literature [9] presented the concept of the transformer economic life from the transformer economic operation's angle It points out that the quantitative assessment of the economic life of transformer, through dynamic comparison, obtains the transformer running factor at different time, different load characteristics, and different operation mode after the implementation, management concept of the best economic life of the biggest.

Based on the mechanism analysis of traction transformer economic operation earlier stage[10-11], with the help of Embedded Configuration Software "WYSIW YG(What You See Is What You Get)" advantage, a traction substation as an example, a traction transformer economic operation monitoring system is designed and implement. The simulation results not only realizes the real-time data of traction transformer running state and real-time curve online, can also save the historical data and historical curve, change trend of past conditions of traction transformer reproduction of part state variables, to validate the measurement and control system, Can meet the monitoring data and process of traction transformer economic operation of the electrified railway.

\section{INTRODUCTION MCGS CONFIGURATION SYSTEM}

The MCGS configuration software has the rich animation configuration, extensible interface open, real-time database, software system includes two part configuration and operating environment. Configuration of the equivalent of a complete set of software tools to help the user, application system design and construct their own. The operating environment is in accordance with the MCGS configuration engineering structural configuration of the environment, running in user specified manner, and various processing, complete the user configuration design of the goals and features.

The configuration results storage database area unit, not only is the numerical variables, including feature variables (attributes) and method of operation of the variable, namely the data object. The results of the configuration database by using the object oriented technology, provides the service for the other part, providing all the functional parts of the system data sharing. The results of the configuration of MCGS system has 
been completed the transition to the operating environment from the configuration database, once the configuration is complete, the operating environment and the database of the configuration results can leave configuration environment and run independently on the monitoring computer.

The establishment engineering of MCGS configuration software is consist by the main window, window, window, the user equipment in real time database and operating strategy of the five parts, each part of each configuration operation, do different work, with different characteristics.

\section{EXAMPLES OF THE CONFIGURATION DESIGN}

Before starting the instance configuration engineering system, first for the project are analyzed, in order to grasp the overall structure, process, project implementation function and how to realize these function. The examples of design experience, a lot of the initial contact with the software personnel, lack of understanding of this step, the debugging stage, deletion of variables will appear a lot of problems just passable, should carry out the design of configuration system in the full understanding of engineering background and engineering process.

\section{A. Examples of profiles}

The active power loss with different types, different capacity of traction transformer and different capacity of the same type transformer load reactive power loss, power loss rate and the critical power active power loss and synthesis power loss of real-time data and real-time curve display for the purpose, requirement with the transformer operating screen, operation to meet the requirements of electrical control the site, historical data and historical curve, must have the safety mechanism, system login required permissions management. Parameters of traction transformer examples are shown in Table.1.

TABLE I. PARAMETERS OF EXAMPLES T RACT IONT RANSFORMER.

\begin{tabular}{l|llllll}
\hline$S_{N} /(\mathrm{KVA})$ & $U_{I N} / U_{2 N} /(\mathrm{KV})$ & $I_{I N} / I_{2 N} /(\mathrm{A})$ & $P_{d} /(\mathrm{KW})$ & $P_{K} /(\mathrm{KW})$ & $I_{0}(\%)$ & $U_{K}(\%)$ \\
\hline $50000(\mathrm{~A})$ & $110 / 27.5$ & $262 / 1050$ & 38.4 & 160 & 0.223 & 10.7 \\
\hline $50000(\mathrm{~B})$ & $110 / 27.5$ & $262 / 1050$ & 79 & 245 & 0.9 & 10.8 \\
\hline $20000(\mathrm{C})$ & $110 / 27.5$ & $262 / 1050$ & 25.85 & 130.8 & 0.832 & 1035 \\
\hline
\end{tabular}

B. Structure Control System Framework

The 7 user windows: cover, the economical transformer operation, real-time data and curves of $1 \sim 3$, the statements of historical, his torical curve. Allow three kinds of graphic objects is the graphics and icons and animation member. Allow seven windows open, also can let a user window as the toolbar at the top, or placed at the bottom as a status bar.

The 7 main menus: system management, economic transformer operation, real-time data and curves of $1 \sim 3$, the reports of historical, historical curve. The main window contains the system menu, the system parameters, such as boot parameters, which determine the overall contour and running process of the control engineering.

The 4 sub menus: user login, logout, user management, password modification. Determine the operator, admin istrator and software maintenance staff login and operation authority, guarantee the site after the implementation of the access violation operation, avoid false operation.

The 4 Strategies: start strategy, exit strategy, circular strategy, and historical data. Strategy is to achieve effective control of the means of the system operation process. A framework provides the strategy itself is only system, strategy condition and function blocks and realize the effective control of the system operation process.

\section{Statistical data object}

Software point information is shown in Table.2.

TABLE II. SOFTWARE POINT INFORMATION

\begin{tabular}{|l|l|l|l|l|l|}
\hline $\begin{array}{l}\text { variable } \\
\text { quantity }\end{array}$ & $\begin{array}{l}\text { switch } \\
\text { number }\end{array}$ & $\begin{array}{l}\text { numerical } \\
\text { number }\end{array}$ & $\begin{array}{l}\text { characters } \\
\text { number }\end{array}$ & $\begin{array}{l}\text { Groups of } \\
\text { objects } \\
\text { number }\end{array}$ & $\begin{array}{l}\text { the current } \\
\text { use } \\
\text { number }\end{array}$ \\
\hline 62 & 4 & 51 & 6 & 1 & 50 \\
\hline
\end{tabular}

With respect to the tractor monitoring software for substation thousands of variables, dispatch command center monitoring software of tens of thousands of variables, configuration software for traction transformer economic operation has the capacity of software overhead is small, the configuration cycle is short, practical characteristics.

\section{Making Graphics}

1) Traction transformer economic operation window: (1) Traction transformer, high voltage switchgear, low voltage switchgear: introduced by the object component library. The main e mbody to the electrical rule of traction substation put in traction transformer from high-voltage side to low-voltage side, put off traction transformer from low-voltage side to the high-voltage side. The high-voltage lines into the T connection traction transformer, cold standby, can put in short connected in parallel, vertical supply and cross power in two ways. A traction transformer high voltage switch and a low voltage switch, each of the 2 groups, we can achieve the transformer of the traction substation for electrical locking and control from high-voltage side to low-voltage side. The above function traction substation operator can operate. Also this can be used by administrators operating two vertical supply different traction transformer index comparisons.

(2) The current path: achieved by flow blocks. Once the system is running to open this window, flow block dynamic display is the current path flow, visual effect is good.

(3) The transformer load rate, the main transformer capacity control: through the sliding input device. Traction transformer load rate is in the range between $0 \sim 1$, capacity between 0 50MVA. Traction transformer used in the load capacity of 50MVA economic rate is about $30 \%$, the initial load rate is only $28 \%$. According to this kind of traction transformer overload limit of 2 times 50 MVA capacity upper limit set.

(4) The transformer load rate, the main transformer capacity, low voltage switchgear, low voltage switch 2, high-voltage switch 1 , high voltage switch 2,5 data and chart display: achieved by label component.

2) Data display window: (1)Real time data: implementation of real-time data by free form component 
(2)History data: historical data through history form component

(3) Real time curve: real time curve by real-time curve of component

(4) History curve: through his tory curve of component

\section{E. Process Control}

Through the realization of circular strategy in the script block strategy. Form and structure of operation strategy is similar to that of PLC ladder diagram programming language, but the more graphic, the more object-oriented. The complex functions. The realization process is relatively simple. Programming syntax is similar to ordinary Basic language, in the background by the independent thread to handle.

\section{F. Security Mechanism}

Security management can through the user rights management, project safety management and script programming. Example of the realization of engineering safety management is through by project password. That control by setting group and user to operate authority.

\section{G. Configuration Check}

Wrong configuration will lead to unexpected results, to develop a good habit of checking the accuracy of configuration. Always check the links, check the configuration file before, all configuration after the completion of the work, a unified configuration check for the entire file, problems timely correction.

\section{Simulation TO REALIZE}

Even if the whole file was been through the configuration syntax check, want into configuration running environment, the comprehensive test and check is also necessary. First, the communication check is correctly. Second, engineering is downloaded success fully no false. Third, simulation operation can be done, too. All realized interfaces are shown in Figure.1 Figure.9.

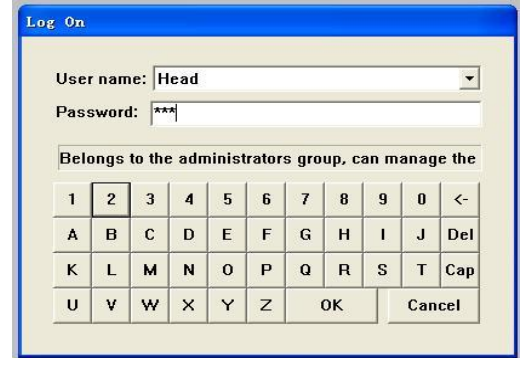

FIGURE I. ENGINEERINGPASSWORD

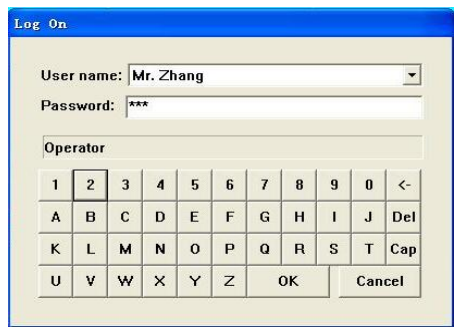

FIGURE II. OPERATOR LOGIN

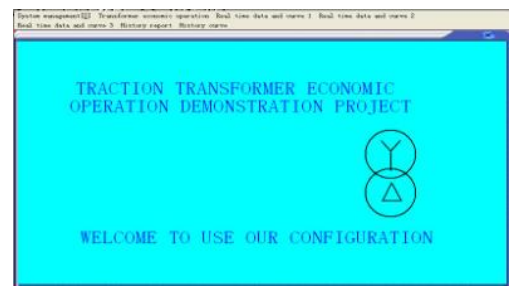

FIGURE III. COVER.

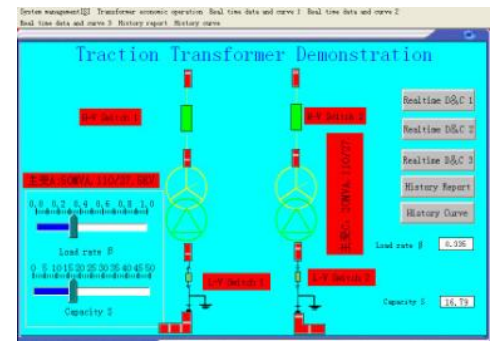

FIGURE IV. RUNNING DYNAMIC TRACTION TRANSFORMER DEMONSTRATION.

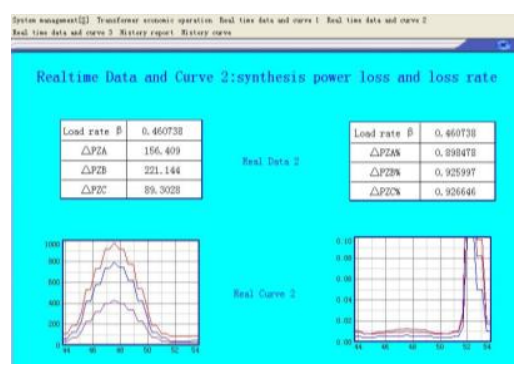

FIGURE V. REAL TIME DATA AND CURVE 2.

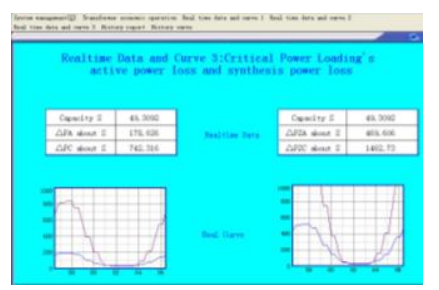

FIGURE VI. REAL TIME DATA AND CURVE 3.

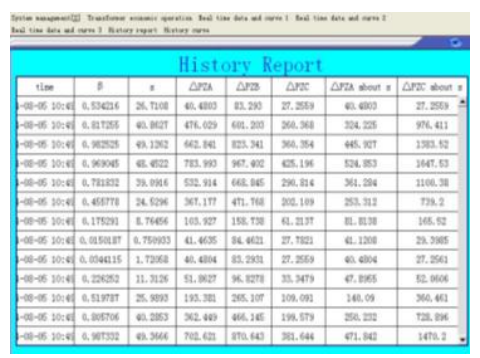

FIGURE VII. HISTORY REPORT.

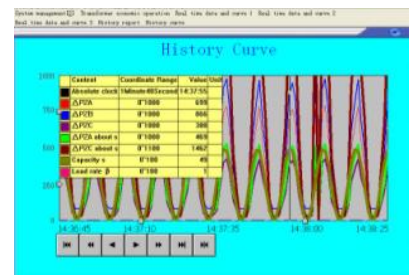

FIGURE VIII. HISTORY CURVE. 


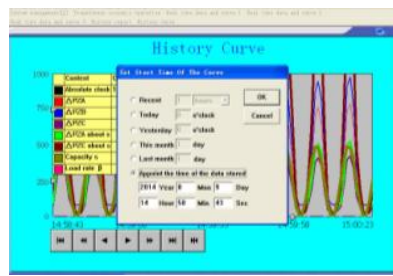

FIGURE IX. ET ST ART TIME OF HIST ORY CURVE.

\section{THE NEXT STEP OF WORK}

This example does not take into account the alarm setting permissions. The protection operation authority of traction transformer has remote (scheduling command center remote control), direct (in the traction substation control panel direct manipulation) and single alone (operation protection body unit) three kinds of mode of operation. Protection setting requires overall consideration, hand operation. While the alarm thresholds need to import from an external database. An economic indicator in the transformer is not involved in running the alarm problem. The next research direction is the external database import and internal database data the second time processing.

\section{CONCLUSION}

Aimed at the electrified railway traction transformer economic operation analysis to quantify indicators and trends reproduction and other issues, the configuration control system is designed based on energy consumption analysis of the traction transformer economic operation. Examples showed the advantage is through historical statements and history curve can reproduce the processes (variables of load rate and transformer capacity) various power loss data and change trend and so on. The configuration software is rich external interface device; others' embedded systems interface convenience. The configuration engineering reduces the capacity overhead of the traction power supply dispatching and the monitoring system, and can meet the visual requirements for load data and process of the traction transformer economic operation evaluation system. The ord inary electrified railway expansion speed or via $\mathrm{CRH} 、 \mathrm{EMU}$ and heavy haul train and other circumstances, the configuration engineering of the traction transformer state evaluation can shorten the software development cycle, reduce cost, effectively improve the timeliness of as sessment. That is the optimization scheme of transformer protection monitoring of digital upgrade transformation.

\section{ACKNOWLEDGEMENT S}

This work was financially supported by the Ning xia Natural Science Foundation (NZ12139).

\section{REFERENCE}

[1] Yong WANG. Analysis of Tactics about Traction Power Supply System in Long-term Overload State. JOURNAL OF RAILWAY ENGINEERING SOCIETY,No.5(Ser.164),pp.54-57,2012.

[2] Fang ZHANG. Simply Analyzing the Traction Transformer Overload Ability. Electrical Switch, No.1, pp.99-102, 2014.

[3] Rongli WANG. Traction Substation Transformer Overload Analysis and Countermeasures. Traction Power Supply,No.2,pp.131-133,2013.
[4] Zhanyuan HE. Analysis of Traction Transformer Life Loss of the LONGGONG Traction Substation. Traction Power Supply, No.2,pp.111-1115,2013.

[5] Qi WANG, Shaofeng XIE, Jin-bo FENG, et al. Estimate on Voltage Level in Traction Power Supply System of Electrified Railway Traction. Proceedings of the CSU-EPSA, Vol.26, No.1,pp.53-56,2014.

[6] Jianjun ZHANG, Hao CHENG, Weihong XIE. Research on Substation Equipment Online Condition Monitoring Network, Low-voltage Electrical Appliances, No.11,pp.50-54,2013.

[7] Hongbo CHENG, Zhengyou HE, Xiuqing MU. Health Monitoring and Evaluation of Traction Power Supply System for High-Speed Railway Based on Multi-Layer Immune Model. Power System Technology, Vol.36, No.9,pp.95-101,2012

[8] Ling RUAN, Qijia XIE, GAO Shengyou, et al. Application of Artificial Neural Network and Information Fusion Technology in Power Transformer Condition Assessment. High Voltage Engineering, Vol.40, No.3, pp. 822-828,2014.

[9] Yimin JIANG. Brief Discussion on Life Time of Transformer. TRANSFORMER, Vol.50, No.12, pp. 34-38, 2013.

[10] Huige Lai, Xuejun Zhu, Jinshou Yu. Design of the protection system for distributed transformer based on PLC. Automation Instrument, 30(9),pp.52-55, 2009.

[11] Huige Lai, Xuejun Zhu, Jinshou Yu. Analysis and Calculation of the Traction transformer for Economical Operation. Micro Computer Information, 25(5),pp. 307-310, 2009.

[12] ABB Installation and Maintenance instructions ABB Transformers AB Sweden.50MVA L3630.1011-001, Sweden. 